\title{
Rapid Solidification Growth Mode Transitions in Al-Si Alloys by Dynamic Transmission Electron Microscopy
}

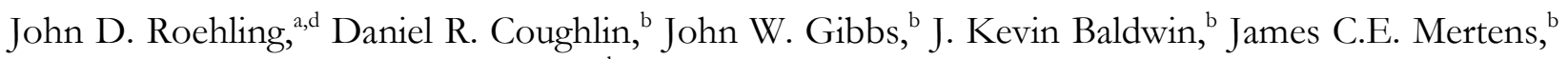
Geoffrey H. Campbell ${ }^{a}$, Amy J. Clarke, ${ }^{\text {b,c }}$ and Joseph T. McKeown ${ }^{a}$

a_-Materials Science Division, Lawrence Livermore National Laboratory, Livermore, CA 94550, USA.

b_-Materials Science and Technology Division, Los Alamos National Laboratory, Los Alamos, NM 87545, USA.

c_-George S. Ansell Department of Metallurgical and Materials Engineering, Colorado School of Mines, Golden, CO 80401, USA.

d_e-mail: roehling1@llnl.gov

\begin{abstract}
In situ dynamic transmission electron microscope (DTEM) imaging of Al-Si thin-film alloys was performed to investigate rapid solidification behavior. Alloy solidification of alloys with compositions from 1 to 15 atomic percent Si was imaged during pulsed laser melting and subsequent solidification. Solely $\alpha$-Al solidification was observed in $\mathrm{Al}-1 \mathrm{Si}$ and $\mathrm{Al}-3 \mathrm{Si}$ alloys, and solely kinetically modified eutectic growth was observed in Al-6Si and Al-9Si alloys. A transition in the solidification mode in eutectic and hypereutectic alloys (Al-12Si and Al-15Si) from nucleated $\alpha$-Al dendrites at lower solidification velocities to planar eutectic growth at higher solidification velocities was observed, departing from trends previously seen in laser-track melting experiments. Comparisons of the growth modes and corresponding velocities are compared with previous solidification models, and implications regarding the models are discussed.
\end{abstract}

\section{INTRODUCTION}

Aluminum silicon (Al-Si) alloys are known for their favorable castability, good wear and corrosion resistance, strength and weldability.[1-3] The microstructure of Al-Si alloys strongly depends on the overall composition and solidification history.[4] Primary aluminum/silicon, irregular eutectic, or dendritic structures can form depending on the composition, solidification velocity and thermal history.[2,5-7] Additionally, rapid solidification can result in kinetically modified structures that do not form under conditions closer to equilibrium. For example, the composition range that eutectic 
structures form is expanded under large thermal gradients and solidification velocities. The solidification velocity also controls the eutectic spacing, which can have an effect on the physical properties. [8-10] Moreover, under very large solidification velocities and thermal gradients partitionless growth, where no solute diffusion can occur, is possible. [11]

Direct prediction of the structures that form under particular conditions has been a continuing challenge for solidification studies. A number of different models have been developed to predict the dendrite tip size, dendrite spacing, eutectic spacing, or transitions between growth modes, such as dendritic to eutectic or eutectic to partitionless growth. [4,10-15] These models are typically steady-state by design and often include adjustable parameters to fit experimental observations; as such, they can cease to be predictive outside a particular range of parameters. And while they have proven to be useful for a number of applications, extensions of these models to a broader range of processing parameters and emerging processes (e.g., additive manufacturing) are needed to continue to develop and expand the field to allow predictive capabilities. A major limitation to the development of these extended models is the lack of experimental observations available for the solidification conditions of interest. Often, ex situ methods that infer solidification velocities are used for model development. Direct observation of the solidification front is possible in some cases using fast camera imaging and X-ray projection, but these are typically limited in spatial resolution to tens of micrometers, which once again limits the range of processing parameters that can be observed. [16,17]

The dynamic transmission electron microscope (DTEM) at Lawrence Livermore National Laboratory (LLNL) has the capability to monitor irreversible events down to tens of nanoseconds and tens of nanometers in time and space, respectively; including solidification. [18-27] This unique 
Here, thin films of Al-Si alloys of various compositions were melted in situ inside the DTEM and imaged during solidification. Compositions ranging from 1-15 at.\% Si (Al-1Si-Al-15Si) were investigated. Studies were performed using a field-of-view (FOV) of approximately $11 \mu \mathrm{m}$ to ensure sufficient resolution to monitor the solidification of single grains. In the hypoeutectic alloys, no growth mode transitions were observed, and solidification proceeded directly with columnar growth of either $\alpha$-Al (Al-1Si and Al-3Si) or columnar growth of eutectic grains ${ }^{\mathrm{a}}$ (Al-6Si and Al-9Si) after the initial solidification of the "mushy" zone. At the eutectic and hypereutectic compositions (Al-12Si and Al-15Si, respectively), a transition between the solidification of nucleated equiaxed-dendritic $\alpha$ $\mathrm{Al}$ grains to planar/columnar ${ }^{\mathrm{b}}$ eutectic grains was observed, accompanied by a transition in the solidification velocity. The reasons for this transition of growth mode are discussed in the

\footnotetext{
a Al-Si alloys display an irregular, branched eutectic structure, and in rapidly solidified alloys the eutectic structure can be "fibrous". ${ }^{3-7}$

b Columnar growth simply refers to directional growth of a grain, whether it is dendritic, cellular, or planar.
} 
framework of previous solidification models, and the need for improved predictive capabilities is outlined.

\section{EXPERIMENTAL METHODS}

Al-Si thin films were deposited simultanously onto square, 0.25 x $0.25 \mathrm{~mm}$ wide, $50 \mathrm{~nm}$ thick $\mathrm{SiN}_{\mathrm{x}}$ windows and lacey carbon TEM grids using DC magnetron sputtering in a chamber with a base pressure of $<6.7 \times 10^{-6} \mathrm{~Pa}\left(5 \times 10^{-8}\right.$ Torr $)$. The process pressure was $0.44 \mathrm{~Pa}\left(3.3 \times 10^{-3}\right.$ Torr $)$. The main sputter target was $\mathrm{Al}-1 \mathrm{at} . \% \mathrm{Si}$, run using a power of $300 \mathrm{~W}$, with a secondary Si target to increase the Si content, run using a power of 25-75 W. The alloy films spanned a composition range from Al1at.\%Si (Al-1Si) to Al-15at.\% Si (Al-15Si), with six nominal compositions investigated: Al-1Si, Al3Si, Al-6Si, Al-9Si, Al-12Si, and Al-15Si. The films on $\mathrm{SiN}_{\mathrm{x}}$ were used for the in situ melting experiments. The lacey carbon TEM grids were used for measurement of the film compositions via energy dispersive x-ray spectroscopy (EDS) in the TEM. The compositions were measured by collecting spectra from five random areas of the metal alloy that were over holes in the carbon film and taking the average. The target and measured compositions are given in Table 1. Deposited alloy film thicknesses were approximately $80-100 \mathrm{~nm}$. Initial grain sizes were on the order of $50 \mathrm{~nm}$ with no preferred crystallographic orientation.

Table 1: Nominal (Target) and measured compositions of the Al-Si thin films

\begin{tabular}{|c|c|}
\hline Target composition (atomic $\%)$ & Measured Composition $^{\text {a }}$ \\
\hline Al-1Si & $1.1 \pm 0.2$ at $\%$ \\
\hline Al-3Si & $2.6 \pm 0.1$ at $\%$ \\
\hline Al-6Si & $5.7 \pm 0.3$ at $\%$ \\
\hline Al-9Si & $8.4 \pm 0.5$ at $\%$ \\
\hline Al-12Si & $10.8 \pm 0.9$ at $\%$ \\
\hline Al-15Si & $14.0 \pm 0.2$ at $\%$ \\
\hline
\end{tabular}

${ }^{a}$ Errors are 1 standard deviation from the mean of 5 measurements from random areas on the film.

The films were melted in situ using a $1064 \mathrm{~nm} \mathrm{Nd:YAG} \mathrm{laser} \mathrm{with} \mathrm{a} 15$ ns full-width half maximum

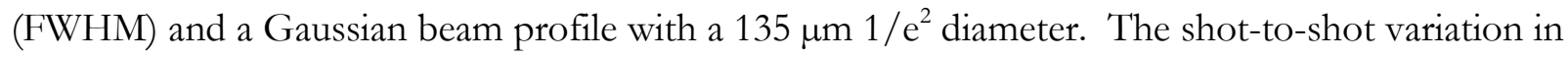


the melting laser energy was $\sim 10 \%$. As each alloy composition required a different energy to achieve melting due to differences in thermal and optical properties, the melt pool size was held approximately constant for all alloy compositions. The DTEM was operated using an accelerating voltage of $200 \mathrm{kV}$. DTEM imaging was carried out using 50 ns electron pulses with either 1 or $2.5 \mu \mathrm{s}$ interframe time-spans between the end of one electron pulse to the beginning of the next. Nineframe movies of a single melting/solidification event were collected with a user-defined delay between the initial melting laser pulse and the first electron pulse. In the DTEM figures shown, specific frames were selected from nine-frame acquisitions to highlight particular features of the solidification process. The full nine-frame Movie Mode data can be found in the Supplementary Material. A schematic of the experimental setup is shown in Figure 1. For further details of the DTEM technique, see Refs. 18-27.

\footnotetext{
Figure 1: (a) Diagram of the $\mathrm{SiN}_{\mathrm{x}}$ window substrates and deposited metal alloy films, with the cross-section depicted underneath. (b) A simplified schematic of the DTEM instrument showing the acquisition of a time sequence by deflecting each electron pulse to a different area on the camera. (c) A diagramed time sequence of the melting of the alloy film by the sample drive laser, the melt pool geometry, and the subsequent solidification process. Note the metal film is completely melted down to the $\mathrm{SiN}_{\mathrm{x}}$ surface and heat flow is in the plane of the film, preferentially through the metal alloy (blue arrows).

Post-mortem energy filtered TEM (EFTEM) mapping was carried out using the jump-ratio method with a FEI Titan transmission electron microscope (TEM) operating at an accelerating voltage of $300 \mathrm{kV}$ and equipped with a Gatan image filter (GIF). Bright-field TEM images were acquired in the DTEM (a modified JEOL 2000FX TEM) operating at $200 \mathrm{kV}$ in conventional thermionic emission mode.
}

\section{RESULTS}

\subsection{Hypoeutectic Al-Si}

The sample melting laser used a Gaussian profile with a 1/ $\mathrm{e}^{2}$ diameter of approximately $135 \mu \mathrm{m}$, with a 45 degree angle of incidence on the sample. This resulted in an elliptical melt pool with a 
Figure 2 shows the solidification of an Al-1Si thin-film starting at $0.00 \mu$ s (the first imaging pulse was coincident with the laser melting pulse). The initial solidification of the mushy region can be seen by the small grains rapidly appearing at $2.10 \mu$ s. If any solid phase was present in the FOV at $0.00 \mu \mathrm{s}$, it is not visible because of a small size and low contrast due to the surrounding liquid. By $4.30 \mu$ s, a planar solid-liquid interface has been established and solidification of columnar grains proceeds. EFTEM maps of these melt pools show no resolvable solute segregation, indicating that only $\alpha-\mathrm{Al}$ formed (not shown). Similar results were obtained in the DTEM movies and EFTEM maps (see Figure S3 in the Supplementary Material) for the Al-3Si alloy. No transition in the solidification mode after the solidification of the "mushy" zone was observed in either alloy.

\footnotetext{
Figure 2: Solidification of an Al-1Si alloy. The solidification of the "mushy" zone occurs between 0.00 and $2.10 \mu \mathrm{s}$. The dotted line shows the approximate location of the solid-liquid interface. The white arrow shows the direction of solidification, heat flow is in the opposite direction. All scale bars are $5 \mu \mathrm{m}$.
} 
Figure 3 shows solidification in an Al-6Si thin-film alloy after the initial "mushy" region has solidified, beginning at $8.00 \mu$ s. By $10.10 \mu$ s a slight advance in the planar solidification front is observed, becoming more clear by $14.30 \mu \mathrm{s}$. A planar solid-liquid interface developed and planar/columnar eutectic growth occurred thereafter. EFTEM maps clearly show that a kinetically modified eutectic growth mode proceeded through the entire solidification process (see Supplementary Material, Figure S9). This was also observed for the Al-9Si alloy (Figure S10). As with the Al-1Si and Al-3Si, no transition in growth mode after the initial solidification of the "mushy" zone was observed for the Al-6Si or Al-9Si alloys.

Figure 3: Solidification of an Al-6Si alloy. The solidification of the "mushy" zone has already occurred at $8.00 \mu$ s and columnar growth begins at $12.20 \mu \mathrm{s}$. The black dotted line denotes the location of the solid-liquid interface. The white arrow shows the direction of solidification, heat flow is in the opposite direction. All scale bars are $5 \mu \mathrm{m}$.

\subsection{Eutectic and Hypereutectic AlSi}

The Al-12Si and Al-15Si alloys exhibited a different solidification behavior from that observed in the hypoeutectic alloys. For these alloys, after the "mushy" zone solidified, two different growth modes were observed. Figure 4a shows the beginning of the solidification process at the edge of the melt pool in an Al-12Si alloy, beginning with the partially molten pool rapidly solidifying into small, equiaxed grains. This can be observed to occur between 2.55 and $7.65 \mu$ s in Figure 4a. Again, within the FOV at $2.55 \mu$ s, any existing solid is small enough that contrast is low due to the surrounding liquid. By $7.65 \mu$ s, the molten regions around the small grains have solidified and these grains are now visible. Following this, a few larger grains of solid nucleate and grow by $12.75 \mu$ s. This continues until $17.85 \mu$ s, with the larger equiaxed grains having reached their final shape by this time. The final structure of these grains can be confirmed in the after image of the solidified melt pool at the right in Figure 4a. 
A second experiment shows an area further into the center of the melt pool at a later time (Figure 4b). The growth of the large nucleated grains can be seen to continue at $20.00 \mu$ s and continue to grow until $30.65 \mu$ s. A similar shape and size of grains as in the previous experiment was observed. One grain was observed to nucleate ahead of the solid-liquid interface at $20.00 \mu$ s. Growth of the nucleated grains and simultaneous growth of surrounding eutectic occurred until the solidification mode rapidly changed to planar/columnar growth, as seen between 30.65 and $35.75 \mu$ s in the timeresolved images of Figure 4b. The final microstructures (right-hand images of Figure 4a and 4b) were similar. The solidification velocity of the nucleating equiaxed $\alpha$-Al grains was $\sim 0.09 \mathrm{~m} / \mathrm{s}$ (averaged from multiple growing grains). During the transition from equiaxed growth to the first stage of planar/columnar growth, the solidification velocity accelerated to $\sim 0.39 \mathrm{~m} / \mathrm{s}$.

A final experiment (Figure 4c) moves even further toward the center of the melt pool (and thus further out in time) to reveal a fully planar solidification front. From 32.55 to $47.85 \mu$ s, the solidliquid interface moves from left to right, opposite the direction of heat extraction. Due to a large temperature gradient (the initial temperature gradient after the melting laser pulse is on the order of $10^{7} \mathrm{~K} / \mathrm{m}$, cooling rates were on the order of $10^{7} \mathrm{~K} / \mathrm{s}$, determined by finite-element modeling) the solidification front was stable to small perturbations, and planar/columnar growth continued until the end of solidification. The solidification velocity was $0.4-0.5 \mathrm{~m} / \mathrm{s}$ near the end of solidification. The solidified columnar grains met in the center of the melt pool along a central line, as seen in Figure 4c. Similar solidification modes and features were observed in the Al-15Si alloy (see figure S8 in the Supplementary Material).

Figure 4: Time-resolved image sequence of solidification in Al-12Si thin film alloys from three separate experiments with different starting times and areas of observation (indicated by the black circles) at the edge of the melt pool. The white arrow shows the direction of solidification, the black dotted lines denote the location of the solid-liquid interface, the black dotted ellipse shows the center of the melt pool, and the white line denotes the location of the solidified "mushy" zone. 
The solidification of the mixed region a) occurs between 2.55 and $7.65 \mu$ s, followed by the nucleation of larger grains ahead of the liquid-solid interface (bounded by the black and white dotted lines). b) Nucleation and growth of the larger grains, sometimes ahead of the solid-liquid interface (black arrow, upper left), is followed by a transition to planar/columnar growth between 25.55 and 30.65 us. c) Fully planar growth is observed thereafter, to the end of solidification. All scale bars shown are all $5 \mu \mathrm{m}$.

Figure 5 shows silicon K-edge EFTEM maps acquired from solidified Al-12Si and Al-15Si melt pools. The silicon signal shows up as bright areas and highlights the location of the Si phase. The halo of Si demonstrates the location of the nucleated equiaxed-dendritic $\alpha$-Al along the initial edge of the melt pool during the early stages of solidification. The nucleated $\alpha$-Al grains grew, toward the center of the melt pool, before switching to eutectic growth over a length scale of a few micrometers. Careful examination of the time-resolved DTEM images reveals that as the nucleated grains grow outward, growth between the grains also occurs simultaneously (see Supplementary Material, figure S6). This interdendritic eutectic growth is clearly observed between specific $\alpha-\mathrm{Al}$ grains in Figure 5a. Inspection of the EFTEM maps of Figure 4 reveals an increase in the background intensity in the eutectic regions relative to that of the $\alpha$-Al regions (eutectic vs. nucleated dendritic). The increased background intensity is due to higher silicon content trapped in the eutectic $\alpha$-Al phase. The EFTEM map makes obvious the change in the partition coefficient when the growth mode transitions from dendritic $\alpha$-Al growth to eutectic growth, which measurements from DTEM images indicate occurred rapidly between $0.1 \mathrm{~m} / \mathrm{s}$ and $0.3 \mathrm{~m} / \mathrm{s}$. Increased solute trapping is expected at higher solidification velocities. Similar features were observed in the Al-15Si alloy, with large clusters of the Si phase. The $\alpha$-Al dendrites were also smaller in size and the band (area between white dotted lines, Figure 5) narrower in width, $\sim 4 \mu \mathrm{m}$ for the Al-12Si and $\sim 2 \mu \mathrm{m}$ for the Al-15Si. The smallest eutectic spacing, $\lambda$, that was observed in either alloy was approximately 50 $\mathrm{nm}$ near the center of the melt pool. The solidification velocities of the Al-15Si alloy were similar to those seen in the Al-12Si alloy, but the final planar solidification speed did not accelerate beyond $0.3-0.4 \mathrm{~m} / \mathrm{s}$. 
Figure 5: EFTEM Si maps from the edge of the solidified melt pool in an a) Al-12Si and b) Al-15Si alloy. Si-rich areas appear bright in the elemental maps. The nucleated equiaxed-dendritic $\alpha$-Al can be seen in between the white dotted lines. Interdendritic eutectic (white dotted circles) exists between some $\alpha$-Al grains. The growth switches to eutectic growth inward from the $\alpha$-Al grains. Large clusters of Si-phase are present in the Al-15Si alloy and the $\alpha$-Al grains are smaller than in the Al-12Si and do not extend as far into the melt pool. The scale bars shown are $2 \mu \mathrm{m}$.

\section{DISCUSSION}

For the Al-1Si and Al-3Si alloys, $\alpha$-Al was the only mode of solidification (supersaturated in the Al3Si). In the Al-6Si and Al-9Si alloys, coupled eutectic growth was observed. At the eutectic and hypereutectic compositions, a switch in the growth mode from nucleation of large, equiaxed $\alpha-\mathrm{Al}$ grains at the edge of the melt pool to fully columnar eutectic growth was observed. Due to the high temperature gradient of these experiments, which usually forces directional growth ${ }^{4}$, this transition was not expected. A sizeable amount of work has been performed by researchers on rapidly solidified Al-Si alloys, [2,5-7,33] and comparison with the trends observed in previous experiments are needed to fully understand the results of the current work.

Traditional descriptions of the solidification morphology of Al-Si alloys have been through competitive growth models, assuming steady-state solidification within a certain moving reference frame.[5-7] The competitive growth models assume the highest interface temperature criterion: the selected growth mode is that with the highest solid-liquid interface temperature for a given growth velocity. Also, due to the common marginal stability assumption, higher solidification velocities correspond to a larger undercooling and hence a lower interface temperature. Admittedly, due to the geometry of these experiments, the solidification processes here were not in steady state. The melt pool radius continually decreased and the temperature field constantly evolved. However, using the rule of thumb to predict the distance needed to develop steady-state solute diffusion, 4D/Vk, with $\mathrm{D}$ being the diffusion coefficient in the liquid, $\mathrm{k}$ the equilibrium partition coefficient, and $\mathrm{V}$ the solidification velocity, the solutal fields were fully developed after the solidification front had 


\subsection{Comparisons to competitive growth model}

Previous observations of hypereutectic Al-Si alloys rapidly solidified by laser-melting showed that only eutectic solidification occurred at lower velocities, while at higher velocities dendritic + interdendritic eutectic growth proceeded. The preference for eutectic growth at lower velocities and non-eutectic compositions is due to more rapid growth (i.e., higher interface temperatures) of the eutectic structure compared to dendrites of the primary phase. This leads to the coupled eutectic zone. [4] Dendritic + eutectic growth occurs at a crossing of the interface growth temperatures with increasing solidification velocity, where the dendritic growth temperature is higher than the eutectic growth temperature (the assumption again being that growth occurs at the highest possible temperature during cooling). Predictions of the eutectic to dendritic transition have relied upon models for eutectic and dendritic growth temperatures developed by Trivedi, Magnin, and Kurz (TMK model) and Kurz, Giovanola, and Trivedi (KGT model), respectively. [10,35]Previous work by Pierantoni et al. using these models predicted dendritic growth to overtake eutectic growth at higher velocities for Al-Si alloys. [5] It is therefore unexpected to see nucleated dendrite-like $\alpha$-Al structures appearing at lower velocities than eutectic structures in the DTEM experiments of this work. The TMK and KGT models also predict limits to eutectic and dendritic growth velocities; in these experiments the eutectic growth velocities exceed the predicted limits. 
These observations of the current experiments raise questions about the predictions of previous models:

1. Are the velocity transition/limit predictions valid for these experimental conditions?

2. Why do the dendrites only appear in the eutectic and hypereutectic compositions and not in the hypoeutectic alloys, as observed previously?

3. Why do dendrites of $\alpha-\mathrm{Al}$ form at lower velocities than the eutectic structure?

4. Why do the dendrites nucleate but not continue with directional growth?

As stated earlier, previous work by Pierantoni et al. on Al-Si demonstrated a higher growth temperature for dendrites at higher velocities, whereas in the present experiments, nucleated equiaxed-dendrites appear ahead of the eutectic front, suggesting a higher growth temperature for dendrites at lower velocities. There are a few possible explanations for this behavior. The previous work noted that the temperature gradient used in Al-Si rapid solidification experiments seemed to alter the transition velocity between dendritic/eutectic and purely eutectic growth by comparing their experiments with previous work done on directional solidification. [36,37] Pierantoni et al. used a temperature gradient of $2 \times 10^{6} \mathrm{~K} / \mathrm{m}$, whereas the directional solidification experiments of references 33 and 34 used lower temperature gradients of $\sim 1 \times 10^{4} \mathrm{~K} / \mathrm{m}$, the latter having a lower dendrite/eutectic transition velocity. An initial temperature gradient of greater than $1 \times 10^{7} \mathrm{~K} / \mathrm{m}$ was established during laser melting in the DTEM experiments. The different temperature gradients therefore likely alter the growth temperature/velocity curves of eutectic and/or dendritic growth.[38] in such a way that dendritic growth is favored (i.e., a higher interface temperature) at lower velocities under the larger temperature gradients of the DTEM rapid solidification experiments. By altering the growth temperature/velocity curves, the bounds of the coupled eutectic zone are altered as well. Pierantoni et al. observed coupled eutectic growth in Al-Si alloys between 
$\mathrm{Al}-10 \mathrm{Si}$ and $\mathrm{Al}-20 \mathrm{Si}$ in laser melt tracks, whereas in the DTEM experiments coupled eutectic growth was observed with compositions as low as Al-6Si, seeming to confirm this hypothesis. These observations might also explain why $\alpha$-Al dendrites were not observed in the lower Si content alloys, as the required temperature/velocity for their growth is also altered by the high temperature gradient.

\subsection{Growth mode transition and maximum growth velocity}

The transition from nucleated dendrites + eutectic to eutectic growth with negligible directional growth of the dendrites despite a sharp temperature gradient is unexpected. This behavior is likely due to two major factors. First, the nucleation of the $\alpha$-Al grains could be caused by transient thermal fields due to local recalescence of the liquid, combined with constitutional undercooling, which allowed nucleation of $\alpha-\mathrm{Al}$ to occur. Heterogeneous nucleation due to the substrate is possible but unlikely, due to the amorphous structure of the $\mathrm{SiN}_{\mathrm{x}}$ substrate and the fact that nucleation events were only observed in these two alloys. Constitutional undercooling effects will be greater in the higher Si content alloys because of the higher concentration of solute that gets pushed into the liquid. This is likely the reason that nucleated equiaxed-dendrites are only observed in the eutectic and hypereutectic alloys (Al-12Si and Al-15Si). Second, the lack of directional dendrite growth may be because the maximum growth speed for dendrites was exceeded. In the Al-12Si alloy, dendrite growth stopped at $0.09 \mathrm{~m} / \mathrm{s}$ in the DTEM experiments, which is in reasonable agreement with the maximum of $0.07 \mathrm{~m} / \mathrm{s}$ predicted by Pierantoni et al. [5] However, it must be noted that the maximum eutectic growth speed they predicted for an Al-15.5Si alloy was $\sim 0.065 \mathrm{~m} / \mathrm{s}$, whereas $\sim 0.3 \mathrm{~m} / \mathrm{s}$ was observed for Al-15Si in the DTEM. Therefore, it seems likely that the predicted eutectic limits may not be valid for the DTEM experiments. 


\subsection{Model sensitivity and outlook}

Non-equilibrium phase diagram models used to predict the effects of non-equilibrium solidification on the eutectic to dendritic +eutectic transition can be sensitive to the physical parameters that are used. Pierantoni et al. used an empirical approach that symmetrically narrows the liquidus and solidus curves around the $\mathrm{T}_{0}$ line ( $\mathrm{T}_{0}$ being the temperature at which the liquid- and solid-phase free energies are equal) to predict the eutectic growth temperature according to the following equation:[5]

$$
\frac{c_{L}(V)-C_{T_{0}}}{r_{n}(n)-C_{m}}=\frac{c_{S}(V)-C_{T_{0}}}{n_{n}(n)-C_{T}}
$$

$\mathrm{C}_{\mathrm{L}}(\mathrm{V})$ and $\mathrm{C}_{\mathrm{s}}(\mathrm{V})$ are related to the velocity-dependent partition coefficient, given by: [39]

$$
k(V)=\frac{k_{0}+a_{0} V / D}{1+\pi_{m} V / n}
$$



interface diffusion coefficient $\left(\mathrm{D}=\mathrm{D}_{0} \mathrm{e}^{-\mathrm{Q} / \mathrm{RT}}\right), \mathrm{C}_{\mathrm{L}}(0)$ and $\mathrm{C}_{\mathrm{s}}(0)$ are related to the equilibrium partition coefficient, $\mathrm{k}=\mathrm{C}_{\mathrm{s}} / \mathrm{C}_{\mathrm{L}}$, and $\mathrm{C}_{\mathrm{T}^{0}}$ is the concentration at the $\mathrm{T}_{0}$ line.

Using the Gibbs free energy curves from reference,[40] equations 1 and 2, the physical parameters given in Table 2 , and the lowest measured solidification velocity $(0.1 \mathrm{~m} / \mathrm{s})$, the kinetically modified eutectic composition is predicted to be 12.4 at \% $\mathrm{Si}$ and the metastable eutectic temperature is $570^{\circ} \mathrm{C}$ (relative to the equilibrium eutectic temperature of $575^{\circ} \mathrm{C}$ ). If $\mathrm{a}_{0}$ is changed to $5 \mathrm{~nm}$, the eutectic composition moves to 12.8 at $\% \mathrm{Si}$ and the metastable eutectic temperature to $555^{\circ} \mathrm{C}$. Note that either predicts that primary $\beta$-Si should be forming in the Al-15Si alloy, rather than the experimentally observed $\alpha-\mathrm{Al}$.

Table 2: Physical parameters used in non-equilibrium phase diagram. (from ref 5, 36)

\begin{tabular}{|c|c|c|}
\hline Property & Symbol & Value (units) \\
\hline Diffusion pre-exponential coeff. $\{\mathrm{Si}$ in $\mathrm{Al}\}$ & $\left(\mathrm{D}_{0}\right)$ & $1.64 \times 10^{-7}\left(\mathrm{~m}^{2} / \mathrm{s}\right)$ \\
\hline Diffusion activation energy & $(\mathrm{Q})$ & $(\mathrm{J} / \mathrm{mol})$ \\
\hline Solidification velocity & $(\mathrm{V})$ & $(\mathrm{m} / \mathrm{s})$ \\
\hline Gas constant & (R) & $8.314 \quad(\mathrm{~J} / \mathrm{mol} \mathrm{K})$ \\
\hline Solid-liquid interface length & $\left(a_{0}\right)$ & $1,5,0.5 \quad(\mathrm{~nm})$ \\
\hline Equilibrium partition coefficient & $\{\mathrm{Al}\}$ & $-1.968 \times 10^{-8} \mathrm{~T}^{3}+4.929 \times 10^{-5} \mathrm{~T}^{2}-4.143 \times 10^{-2} \mathrm{~T}+11.82$ \\
\hline Equilibrium liquidus & $\mathrm{C}_{\mathrm{L}}(0)\{\mathrm{Al}\}$ & $-6.004 \times 10^{-7} \mathrm{~T}^{3}+1.362 \times 10^{-3} \mathrm{~T}^{2}-1.134 \mathrm{~T}+360.5$ \\
\hline Equilibrium partition coefficient & $\mathrm{k}_{0} \quad\{\mathrm{Si}\}$ & $5.777 \times 10^{-20} \mathrm{~T}^{3}+1.284 \times 10^{-15} \mathrm{~T}^{2}-3.725 \times 10^{-12} \mathrm{~T}-1.838 \times 10^{-4}$ \\
\hline Equilibrium liquidus & $\mathrm{C}_{\mathrm{L}}(0)\{\mathrm{Si}\}$ & $2.661 \times 10^{-8} \mathrm{~T}^{3}+1.225 \times 10^{-4} \mathrm{~T}^{2}+9.457 \times 10^{-2} \mathrm{~T}+79.69$ \\
\hline
\end{tabular}

A slightly modified approach by Carrard et al. [15] used a modification to Boettinger's response function [41] for dilute alloys with the kinetically modified liquidus composition given by:

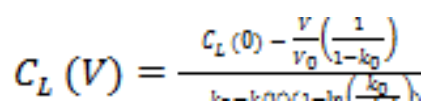

where $\mathrm{V}_{0}$ is approximately the speed of sound in the solid (here, $1000 \mathrm{~m} / \mathrm{s}$ was used). It has been noted that the dilute and concentrated response functions produced similar results.[5] Using an interface distance $\left(\mathrm{a}_{0}\right)$ of $0.5 \mathrm{~nm}$ and a solidification velocity of $0.1 \mathrm{~m} / \mathrm{s}$, the predicted eutectic composition is 19.2 at \% $\mathrm{Si}$ and the metastable eutectic temperature is $509^{\circ} \mathrm{C}$. This seems to more accurately predict the phases forming under the conditions observed in the current DTEM 
experiments and nearly predicts the composition of the formation of primary $\beta$-Si precipitates in laser-track experiments (above 20 at.\%) despite being derived in the dilute solution limit, but cannot be used in the TMK model because of the strong deviation of the liquidus from linearity. [5-7] This simple exercise demonstrates the sensitivity of metastable phase diagram approaches to the response function, the diffusion coefficients, and the assumed interface width.

The extended range of growth modes and growth transitions observed in the present experiments highlights the need and opportunity to further refine well-established models. The ability to access difficult experimental conditions in the DTEM can allow for more precise determination of the parameters needed for competitive growth models, as well as highlight a given model's limitations. Future work is needed to develop better predictive models, such as phase-field approaches that incorporate rapid solidification conditions.

\section{Conclusions}

Studies of solidification of thin-film Al-Si alloys in the TEM revealed some unexpected growth mode transitions. An initial solidification of the mixed phase region ("mushy" zone), was seen in all alloys investigated. This was followed by a transition to planar $\alpha$-Al or eutectic growth for 1 and 3 at. \% Si alloys, and 6 and 9 at.\% Si alloys, respectively. Eutectic growth at compositions as low as Al6Si was not predicted by previous work. For Al-12Si and Al-15Si alloys, after the solidification of the mixed region, nucleated equiaxed-dendrites formed followed by a transition to planar eutectic growth. This growth mode transition was not reported or predicted by previous experiments or models. The difference may be due to the larger temperature gradient present in the Al-Si thin-films. The growth transition was accompanied by a transition in the solidification velocity from 0.09 to $0.39 \mathrm{~m} / \mathrm{s}$ from the dendritic growth and eutectic growth, respectively. The magnitude of the 
measured eutectic growth speed in the Al-15Si alloy was also larger than predicted by the TMK model in ref. 5. These experiments highlight the need to further improve upon well-established competitive growth models, encompassing a wider range of experimental conditions. Direct observations of growth-mode transitions like these will prove useful for future experimental validation of solidification models such as phase-field using rapid solidification conditions.

\section{Acknowledgments}

This work was performed under the auspices of the U.S. Department of Energy, by Lawrence Livermore National Laboratory (LLNL) under Contract No. DE-AC52-07NA27344. Activities and personnel at LLNL were supported by the U.S. Department of Energy, Office of Science, Office of Basic Energy Sciences, Division of Materials Science and Engineering under FWP SCW0974. JDR was supported through the LLNL Laboratory Directed Research and Development Program under project tracking code 15-ERD-006. Work at Los Alamos National Laboratory (LANL) was performed under the auspices of the U.S. Department of Energy by Los Alamos National Security, LLC, under Contract No. DE-AC52-06NA25396. Activities and personnel at LANL were supported by an Early Career award from the U.S. DOE, Office of Basic Energy Sciences, Division of Materials Sciences and Engineering. DTEM sample preparation at LANL was performed at the Center for Integrated Nanotechnologies, an Office of Science User Facility operated for the U.S. DOE Office of Science.

\section{References}

[1] Y. Birol, Microstructural characterization of a rapidly-solidified Al-12wt\% Si alloy, J. Mater. Sci. 31 (1996) 2139-43.

[2] G.P. Dinda, A.K. Dasgupta, J. Mazumder, Evolution of microstructure in laser deposited Al11.28\%Si alloy, Surf. Coat. Technol. 206 (2012) 2152-2160. doi:10.1016/j.surfcoat.2011.09.051. 
[3] S. Hegde, K.N. Prabhu, Modification of eutectic silicon in Al-Si alloys, J. Mater. Sci. 43 (2008) 3009-3027. doi:10.1007/s10853-008-2505-5.

[4] W. Kurz, D.J. Fisher, Fundamentals of Solidification, Trans Tech SA, Switzerland, 1984.

[5] M. Pierantoni, M. Gremaud, P. Magnin, D. Stoll, W. Kurz, The coupled zone of rapidly solidified Al $\square$ Si alloys in laser treatment, Acta Metall. Mater. 40 (1992) 1637-1644. doi:10.1016/0956-7151(92)90106-O.

[6] M. Gremaud, D.R. Allen, M. Rappaz, J.H. Perepezko, The development of nucleation controlled microstructures during laser treatment of AlSi alloys, Acta Mater. 44 (1996) 26692681. doi:10.1016/1359-6454(95)00393-2.

[7] D.R. Allen, M. Gremaud, J.H. Perepezko, Nucleation-controlled microstructural development in Al-Si alloys, Mater. Sci. Eng. A. 226-228 (1997) 173-177. doi:10.1016/S09215093(96)10612-2.

[8] N. Wang, R. Trivedi, Limit of steady-state lamellar eutectic growth, Scr. Mater. 64 (2011) 848851. doi:10.1016/j.scriptamat.2011.01.010.

[9] P. Magnin, R. Trivedi, Eutectic growth: A modification of the Jackson and Hunt theory, Acta Metall. Mater. 39 (1991) 453-467. doi:10.1016/0956-7151(91)90114-G.

[10] R. Trivedi, P. Magnin, W. Kurz, Theory of eutectic growth under rapid solidification conditions, Acta Metall. 35 (1987) 971-980. doi:10.1016/0001-6160(87)90176-3.

[11] R. Trivedi, J.A. Sekhar, Seetharaman, Solidification microstructures near the limit of absolute stability, Metall. Trans. A. 20 (1989) 769-777.

[12] W. Kurz, D.J. Fisher, Dendrite growth at the limit of stability: Tip radius and spacing, Acta Metall. 29 (1981) 11-20.

[13] D. Tourret, A.J. Clarke, S.D. Imhoff, P.J. Gibbs, J.W. Gibbs, A. Karma, Three-Dimensional Multiscale Modeling of Dendritic Spacing Selection During Al-Si Directional Solidification, JOM. 67 (2015) 1776-1785. doi:10.1007/s11837-015-1444-2.

[14] W. Kurz, D.J. Fisher, Dendrite growth in eutectic alloys: the coupled zone, Int. Met. Rev. 24 (1979) 177-204. doi:10.1179/imtr.1979.24.1.177.

[15] M. Carrard, M. Gremaud, M. Zimmermann, W. Kurz, About the banded structure in rapidly solidified dendritic and eutectic alloys, Acta Metall. Mater. 40 (1992) 983-96.

[16] A.J. Clarke, D. Tourret, S.D. Imhoff, P.J. Gibbs, K. Fezzaa, J.C. Cooley, W.-K. Lee, A. Deriy, B.M. Patterson, P.A. Papin, K.D. Clarke, R.D. Field, J.L. Smith, X-ray Imaging and Controlled Solidification of Al-Cu Alloys Toward Microstructures by Design, Adv. Eng. Mater. 17 (2015) 454-459. doi:10.1002/adem.201400469.

[17] D.M. Herlach, P.K. Galenko, Rapid solidification: in situ diagnostics and theoretical modelling, Mater. Sci. Eng. A. 449-451 (2007) 34-41. doi:10.1016/j.msea.2006.02.303.

[18] T. LaGrange, M.R. Armstrong, K. Boyden, C.G. Brown, G.H. Campbell, J.D. Colvin, W.J. DeHope, A.M. Frank, D.J. Gibson, F.V. Hartemann, J.S. Kim, W.E. King, J.E. Pyke, B.W. Reed, M.D. Shirk, R.M. Shuttlesworth, B.C. Stuart, B.R. Torralva, N.D. Browning, Single-shot dynamic transmission electron microscopy, Appl. Phys. Lett. 89 (2006) 044105.

[19] T. LaGrange, G.H. Campbell, B.W. Reed, M. Taheri, J.B. Pesavento, J.S. Kim, N.D. Browning, Nanosecond time-resolved investigations using the in situ dynamic transmission electron microscope (DTEM), Ultramicroscopy. 108 (2008) 1441-49.

[20] J.S. Kim, T. LaGrange, B.W. Reed, M. Taheri, M.R. Armstrong, W.E. King, N.D. Browning, G.H. Campbell, Imaging of transient structures using nanosecond in situ TEM, Science. 321 (2008) 1472-75.

[21] G.H. Campbell, T. LaGrange, J.S. Kim, B.W. Reed, N.D. Browning, Quantifying transient states in materials with the dynamic transmission electron microscope, J. Electron Microsc. (Tokyo). 59 (2010) S67-S74.

[22] A. Kulovits, J.M.K. Wiezorek, T. LaGrange, B.W. Reed, G.H. Campbell, Revealing the transient states of rapid solidification in aluminum thin films using ultrafast in situ transmission electron microscopy, Philos. Mag. Lett. 91 (2011) 287-296.

[23] T. LaGrange, B.W. Reed, M.K. Santala, J.T. McKeown, A. Kulovits, J.M.K. Wiezorek, L. Nikolova, F. Rosei, B.J. Siwick, G.H. Campbell, Approaches to ultrafast imaging of transient materials processes in the transmission electron microscope, Micron. 43 (2012) 1108-1120. 
[24] M.K. Santala, B.W. Reed, S. Raoux, T. Topuria, T. LaGrange, G.H. Campbell, Irreversible reactions studied with nanosecond transmission electron microscopy movies: Laser crystallization of phase change materials, Appl. Phys. Lett. 102 (2013) 174105.

[25] J.T. McKeown, A.K. Kulovits, C. Liu, K. Zweiacker, B.W. Reed, T. LaGrange, J.M.K. Wiezorek, G.H. Campbell, In situ transmission electron microscopy of crystal growth-mode transitions during rapid solidification of a hypoeutectic Al-Cu alloy, Acta Mater. 65 (2014) 5668.

[26] K. Zweiacker, M.A. Gordillo, C. Liu, J.T. McKeown, T. LaGrange, B.W. Reed, G.H. Campbell, J.M.K. Wiezorek, Quantitative phase analysis of rapid solidification products in Al$\mathrm{Cu}$ alloys by automated crystal orientation mapping in the TEM, Microsc. Microanal. 21 (2015) 1465-66.

[27] T. LaGrange, B.W. Reed, D.J. Masiel, Movie-mode dynamic electron microscopy, MRS Bull. 40 (2015) 22-28.

[28] J.T. McKeown, K. Zweiacker, C. Liu, D.R. Coughlin, A.J. Clarke, J.K. Baldwin, J.W. Gibbs, J.D. Roehling, S.D. Imhoff, P.J. Gibbs, D. Tourret, J.M.K. Wiezorek, G.H. Campbell, TimeResolved In Situ Measurements During Rapid Alloy Solidification: Experimental Insight for Additive Manufacturing, JOM. 68 (2016) 985-999. doi:10.1007/s11837-015-1793-x.

[29] K. Zweiacker, J.T. McKeown, C. Liu, T. LaGrange, B.W. Reed, G.H. Campbell, J.M.K. Wiezorek, Determination of crystal growth rates during rapid solidification of polycrystalline aluminum by nano-scale spatio-temporal resolution in situ transmission electron microscopy, J. Appl. Phys. 120 (2016) 055106. doi:10.1063/1.4960443.

[30] Zhang, X., Grigoropoulos, C. P., Thermal conductivity and diffusivity of free-standing silicon nitride thin films, Rev. Sci. Instrum. Vol 66 (1994) 1115-1120.

[31] B.L. Zink, F. Hellman, Specific heat and thermal conductivity of low-stress amorphous Si-N membranes, Solid State Commun. 129 (2004) 199-204.

[32] P. Olafsson, R. Sandstrom, A.. Karlsson, Comparison of experimental, calculated and observed values for electrical and thermal conductivity of aluminium alloys, J. Mater. Sci. 32 (1997) 4383-4390. doi:10.1023/A:1018680024876.

[33] F.A. Espana, V.K. Balla, A. Bandyopadhyay, Laser processing of bulk Al-12Si alloy: influence of microstructure on thermal properties, Philos. Mag. 91 (2011) 574-588.

[34] Fisher, D.J. and Kurz, W., Fundamentals of Solidification, 3rd ed., Trans Tech Publications, 1992.

[35] W. Kurz, B. Giovanola, R. Trivedi, Theory of microstructural development during rapid solidification, Acta Metall. 34 (1986) 823-830. doi:10.1016/0001-6160(86)90056-8.

[36] H.A.H. Steent, A. Hellawell, Structure and properties of aluminium-silicon eutectic alloys, Acta Metall. 20 (1972) 363-370. doi:10.1016/0001-6160(72)90030-2.

[37] O.A. Atasoy, F. Yilmaz, R. Elliott, Growth structures in aluminum-silicon alloys I. The coupled zone, J. Cryst. Growth. 66 (1984) 137-46.

[38] B. Toloui, A. Hellawell, Phase separation and undercooling in Al-Si eutectic alloy-the influence of freezing rate and temperature gradient, Acta Metall. 24 (1976) 565-573. doi:10.1016/0001-6160(76)90102-4.

[39] M.J. Aziz, T. Kaplan, Continuous model for interface motion during alloy solidification, Acta Metall. 36 (1988) 2335-47.

[40] J.L. Murray, A.J. McAlister, The Al-Si (Aluminum-Silicon) system, Bull. Alloy Phase Diagr. 5 (1984) 74-84. doi:10.1007/BF02868729.

[41] W.J. Boettinger, S.R. Coriell, R.Trivedi in Proc. $4^{\text {th }}$ Conf. Rapid Solidification Processing: Principles and Technologies, Santa Barbara (edited by R. Mehrabian and P. A. Parrish) (1987). 


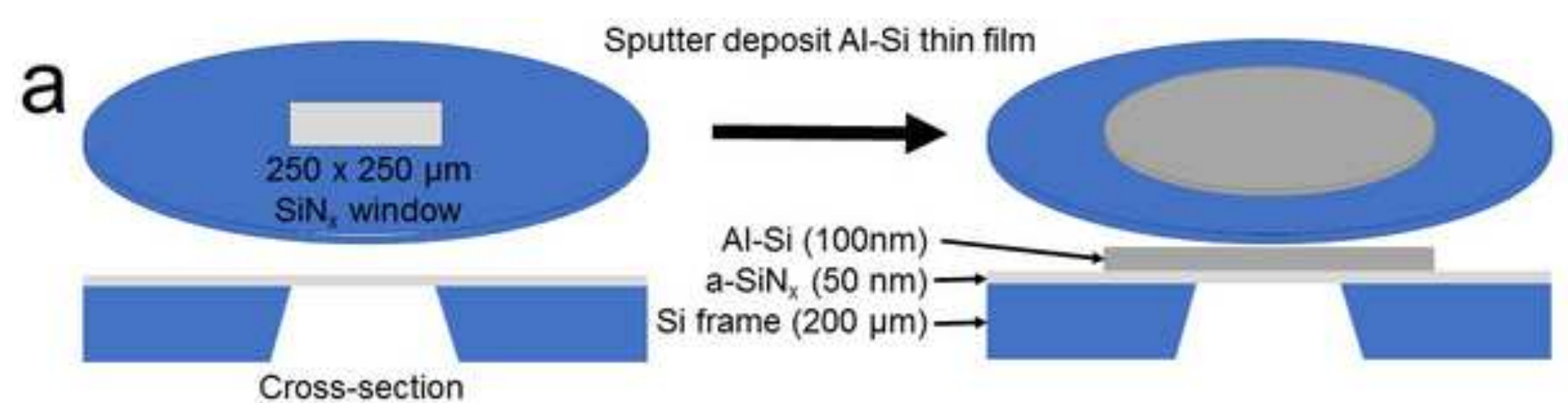

b

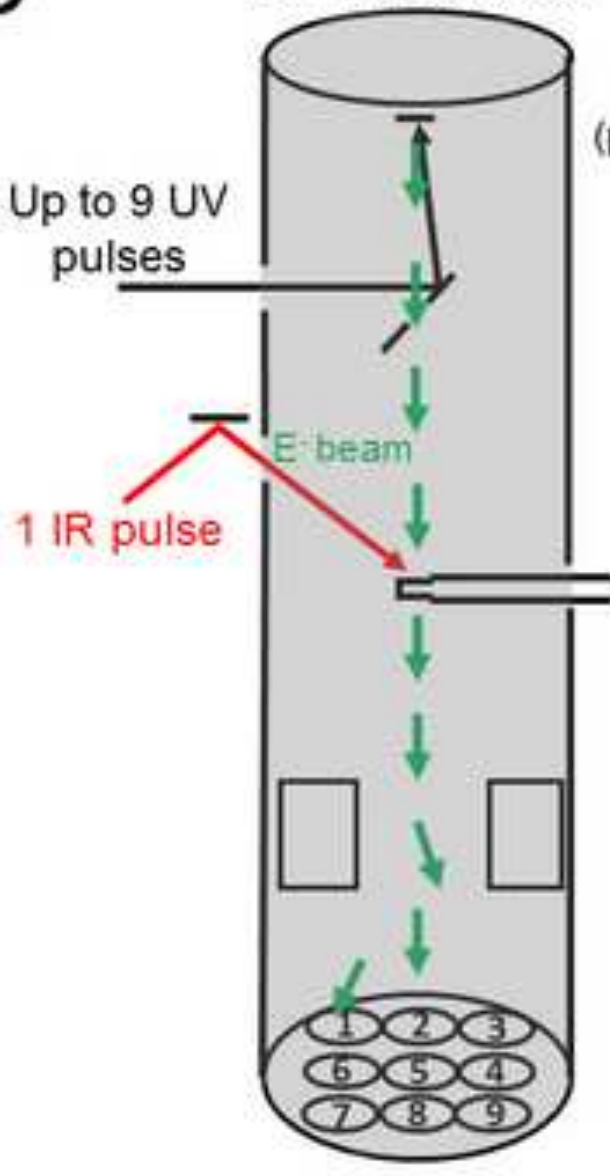

Disc cathode photoemission or thermionic emission)

Mo mirror Specimen rod

\section{E'beam} deflectors CCD

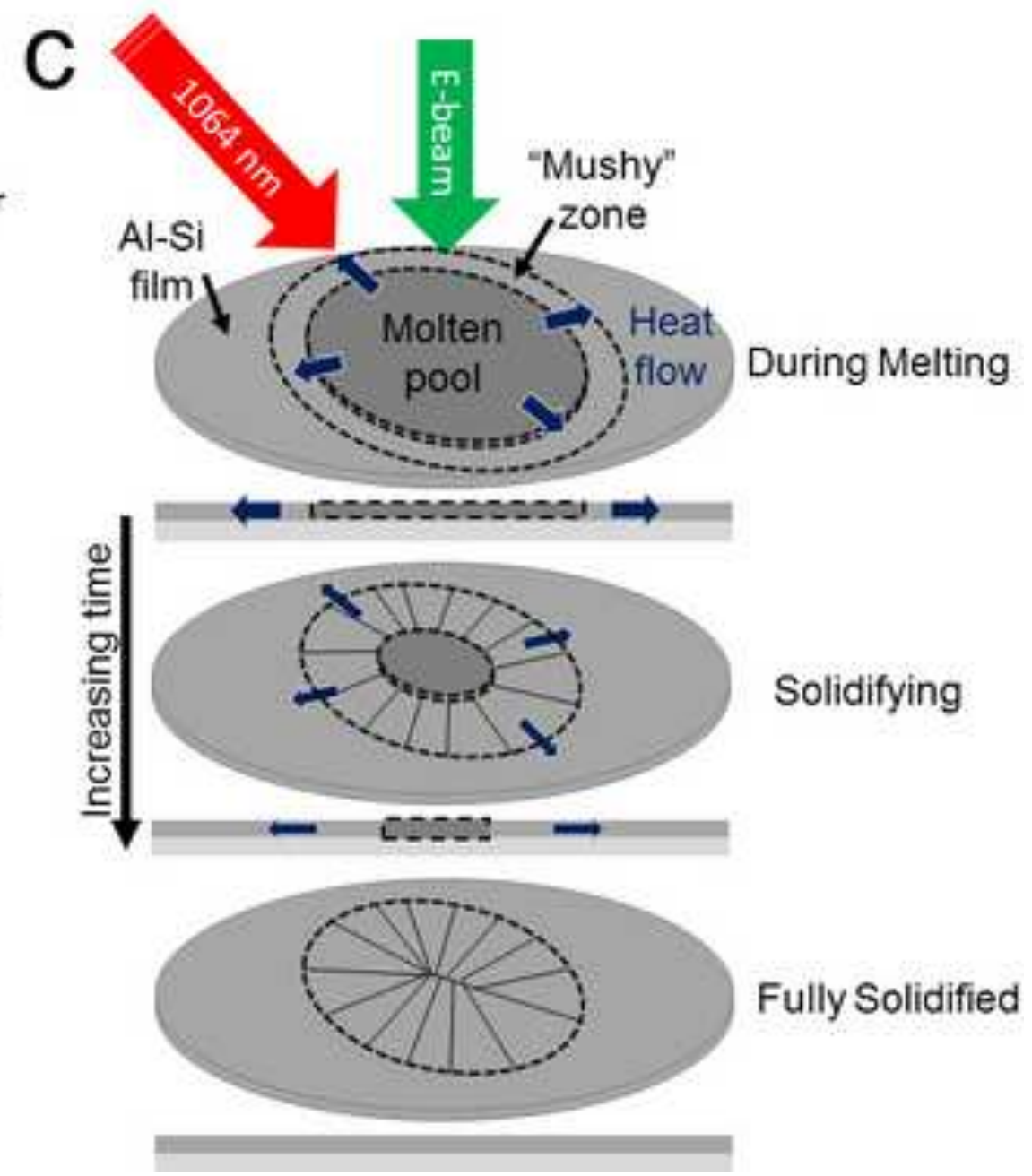




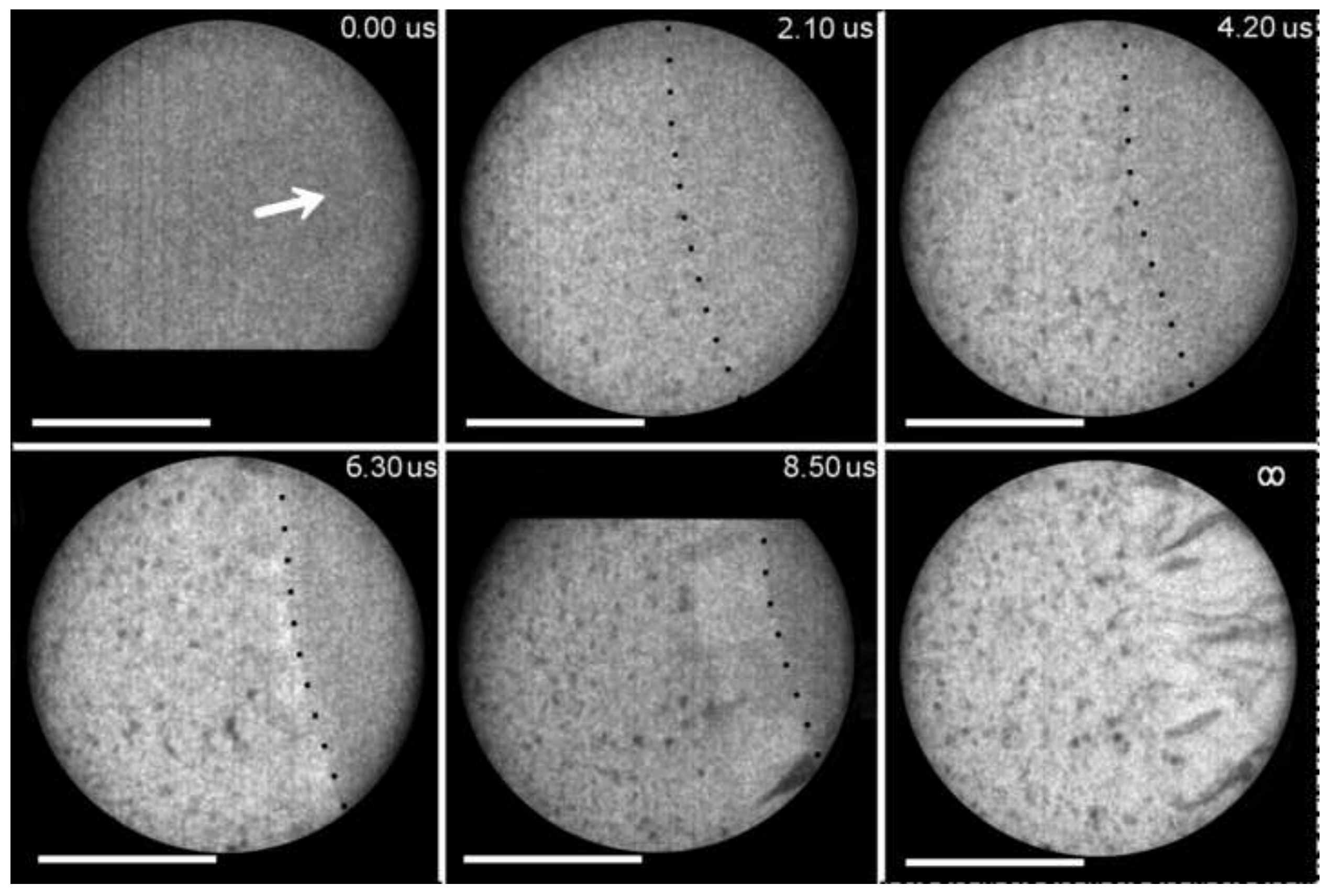



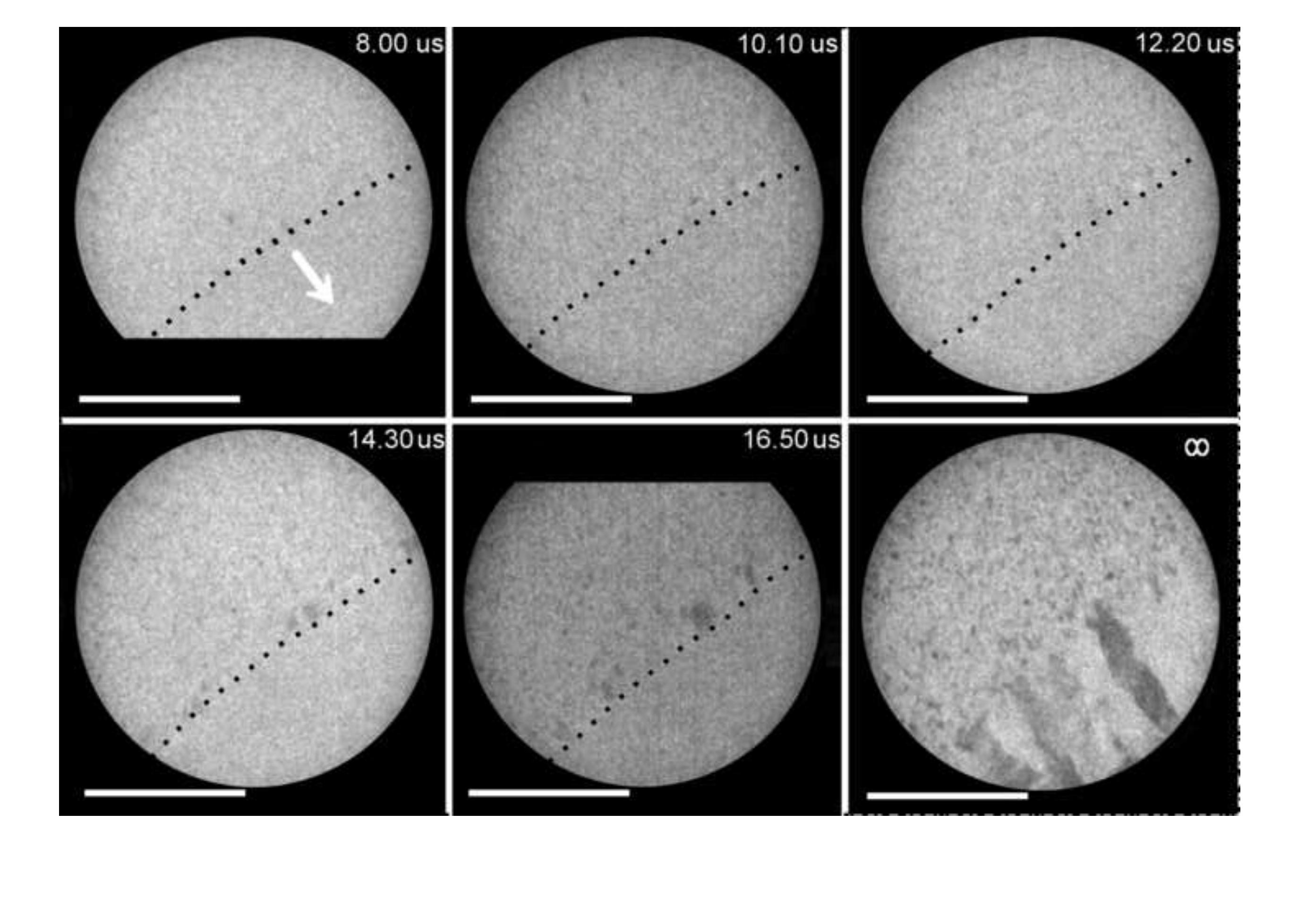

\section{Figure}

.

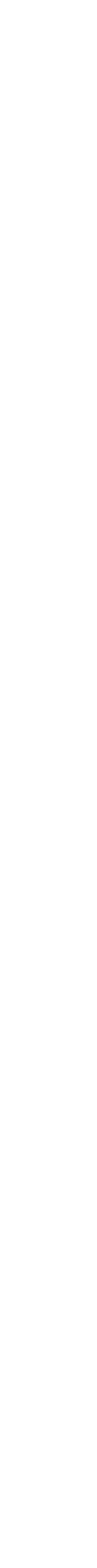



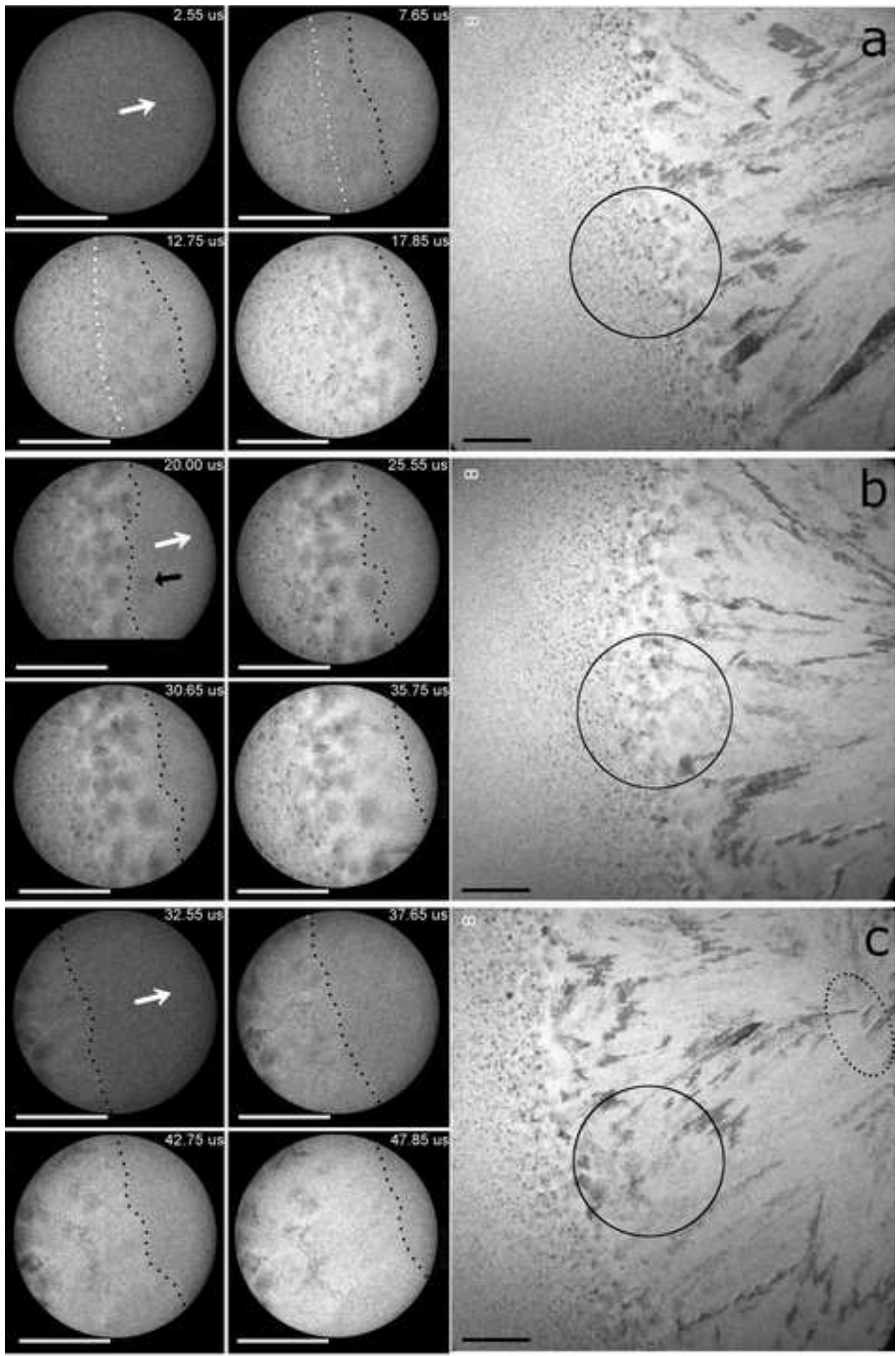


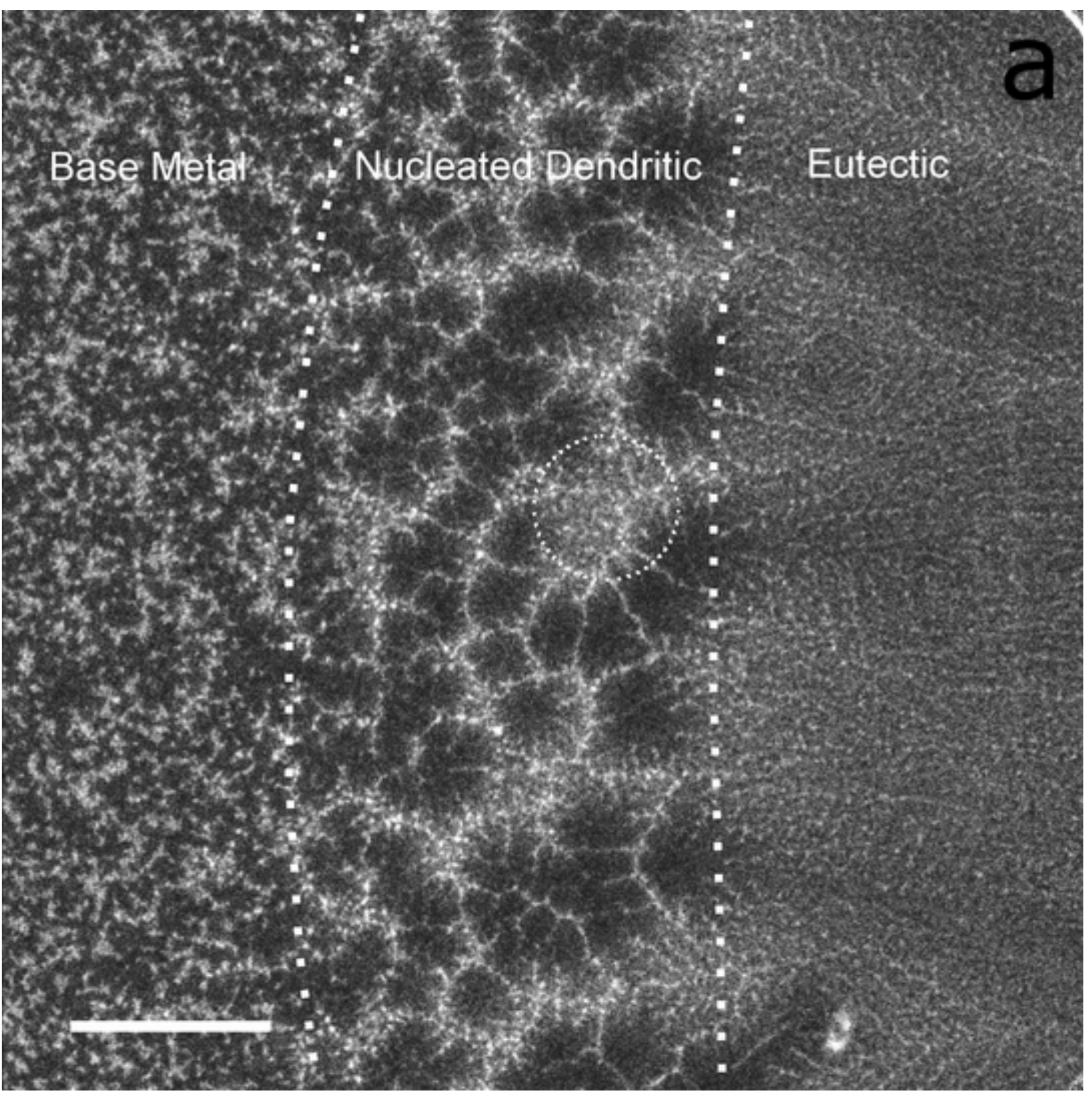


S Base Metal

a 502000

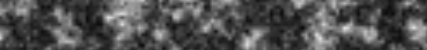

(3) Nugleated Dencitic.

15. 

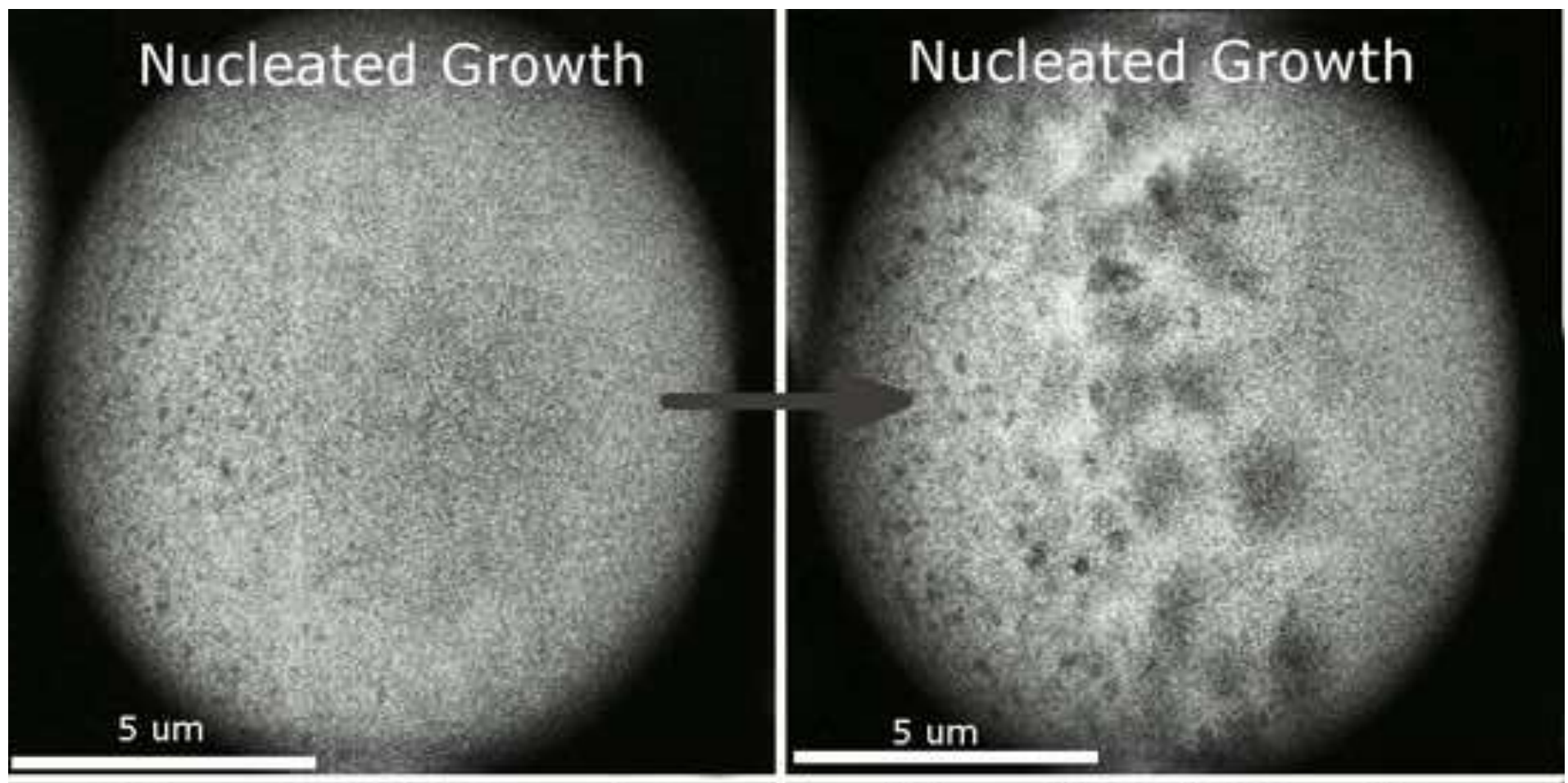

Directional Growth

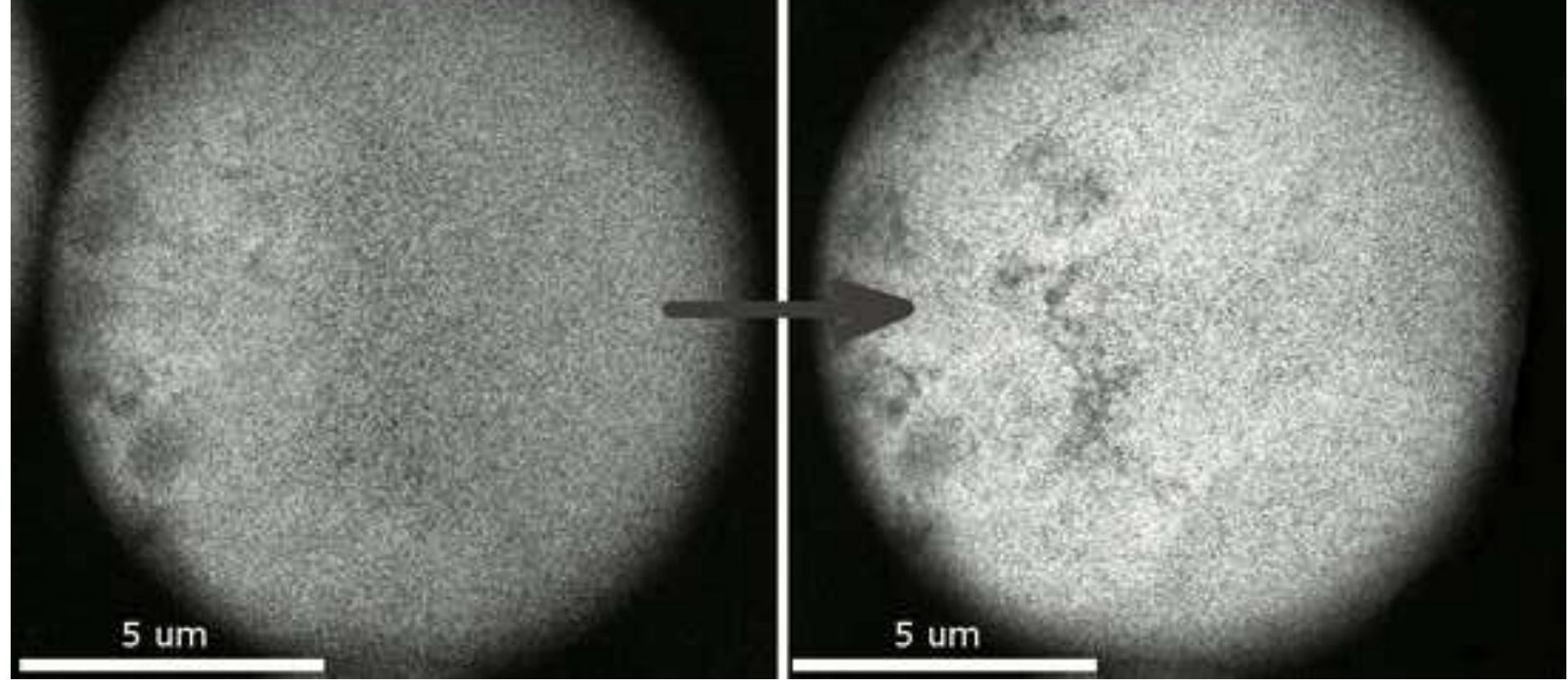

